\title{
PRIORITAS PENINGKATAN PRASARANA BERKELANJUTAN PERUMAHAN BUKIT BARUGA DI MAKASSAR
}

\author{
Adithya Yudistira ${ }^{1}$ \\ ${ }^{1}$ Prodi Arsitektur, Fakultas Teknik, Universitas Muslim Indonesia
}

\begin{abstract}
Abstrak
Penelitian ini bertujuan menganalisis ketersediaan prasarana berkelanjutan perumahan permukiman dan prioritas peningkatan prasarana perumahan permukiman. Penelitian ini bersifat deskriptif komparatif. Penelitian dilakukan pada perumahan Bukit Baruga Kecamatan Manggala Kelurahan Antang. Pengumpulan data dilakukan melalui observasi, wawancara dan kuisioner. Sampel yang diambil adalah kepala rumah tangga yang dipilih secara sampel klaster. Data dianalisis dengan analisis AHP (Analytic Hierarchy Process). Hasil penelitian menunjukkan bahwa kondisi ketersediaan prasarana transportasi, drainase, air bersih dan sanitasi perumahan secara teknis sudah memadai namun belum sepenuhnya memenuhi standar berkelanjutan. Hasil analisis prioritas peningkatan menggunakan AHP menunjukkan prioritas pertama peningkatan prasarana transportasi dengan bobot 0,31 , prioritas kedua prasarana sampah dan air limbah dengan bobot 0,27 , prioritas ketiga prasarana air bersih dengan bobot 0,25 dan prioritas keempat prasarana drainase dengan bobot 0,17 .
\end{abstract}

Kata kunci: Prioritas Peningkatan, Prasarana Berkelanjutan, Analisis AHP.

\begin{abstract}
The aim of the study is to analyze the availability of sustainable infrastructure of dwelling home and to analyze the priority of improvement of dwelling house infrastructure. The research type was a descriptive comparative study. The research was conducted at Manggala District Housing of Pondok Baruga Antang. Data were collected with observation, interviews, and questionnaires to assess the availability of sustainable infrastructure. Respondents were household heads or residents selected as cluster samples. The method of analysis was Analytic Hierarchy Process (AHP) to determine the priority of sustainable infrastructure development. The results of the research indicated that the availability of transportation infrastructure, drainage, water and housing sanitary are technically adequate but had not fully met the sustainability standards. The results of the AHP analysis indicated that the first priority is transport infrastructure improvement with a weight of 0.31, Second priority is garbage and wastewater infrastructure 0.27, third priority is water infrastructure 0.25, and forth priority is drainage infrastructure 0.17 .
\end{abstract}

Keywords: Priority Development, Sustainable Infrastructure , AHP Analysis

\section{PENDAHULUAN}

Masalah pemanasan global dan penurunan kualitas lingkungan saat ini menjadi prioritas bagi setiap negara di dunia untuk ditangani secara maksimal. Permasalahan lingkungan ini sebagai akibat dari aktifitas-aktiitas industri maupun konstruksi yang dilakukan dalam usaha pemenuhan kebutuhan hidup manusia sehari-harinya.

Pembangunan perumahan dan permukiman dalam lingkungan perkotaan dapat menjadi ruang lingkup permasalahan tersendiri. Menurut prediksi Robert (2006) prosentase penduduk Indonesia yang tinggal di perkotaan pada 2008 mencapai 50\% dari total penduduk. Pemikiran mengenai dampak lingkungan yang terjadi akibat pembangunan, terutama dalam lingkungan perkotaan memberikan sebuah perubahan mendasar dalam pembangunan untuk memfasilitasi prinsip berperilaku ramah lingkungan. Pembangunan infrastruktur hijau merupakan usaha menjaga pelestarian lingkungan dan keberlanjutan pembangunan perumahan dan permukiman di lingkungan perkotaan. Menurut Mark et al. (2001) infrastruktur hijau adalah kerangka ekologi yang diperlukan untuk lingkungan, sosial dan ekonomi berkelanjutan. Prasarana berkelanjutan berbeda dari pendekatan konvensional lain untuk perencanaan ruang terbuka karena melihat nilai-nilai konservasi dan tindakan dalam pengembangan lahan, manajemen pertumbuhan dan perencanaan infrastruktur.

Perumahan yang menarik untuk dijadikan lokasi dalam penelitian ini adalah Bukit Baruga yang dikembangkan oleh PT. Baruga Asrinusa Development merupakan salah satu perumahan terbesar di kota Makassar Sulawesi Selatan. Perumahan Bukit Baruga memiliki luas lahan perumahan yang terus dikembangkan dari tahun 1996 hingga saat ini 2013 sebesar $300 \mathrm{Ha}$. Perumahan ini menawarkan konsep perumahan berwawasan lingkungan dengan ruang terbuka hijau yang maksimal. Selama kurang lebih 17 tahun pengembangan perumahan Bukit Baruga tersebut, 
kondisi prasarana dasar perumahan yang tersedia akan berfungsi tidak seoptimal dulu jika tidak dipelihara dengan baik, ditambah jumlah penduduk yang diakomodir hingga saat ini semakin banyak seiring pertumbuhan perumahannya, sehingga tentunya diperlukan perencanaan peningkatan prasarana yang optimal sesuai sasaran kebutuhan dan berkelanjutan bagi masyarakat penghuninya.

Berdasarkan latar belakang di atas, maka rumusan permasalahan yang menjadi bahan kajian dalam penelitian ini yaitu bagaimana ketersediaan prasarana berkelanjutan perumahan Bukit Baruga Makassar dan bagaimana urutan prioritas peningkatan prasarana berkelanjutan perumahan bukit baruga dalam mendukung perumahan yang ramah lingkungan.

Penelitian terdahulu yang terkait dengan penelitian ini dilakukan oleh Massiki (2005) dengan judul penelitian analisis ketersediaan sarana dan prasarana pada lingkungan permukiman, Penelitian yang dilakukan menganalisis ketersediaan dari sarana dan prasarana lingkungan untuk meningkatkan kualitas lingkungan di permukiman padat di Kota Palu.

Tujuan yang ingin dicapai dalam penelitian ini adalah untuk menganalisis ketersediaan prasarana berkelanjutan perumahan Bukit Baruga Makassar serta untuk menyimpulkan urutan prioritas peningkatan prasarana berkelanjutan perumahan Bukit Baruga Makassar.

\section{ISI PENELITIAN}

\subsection{Lokasi dan Rancangan Penelitian}

Penelitian ini dilakukan di Kota Makassar ibu kota Sulawesi Selatan pada Kecamatan Manggala Kelurahan Antang Makassar dengan obyek penelitian perumahan Bukit Baruga. Penetapan lokasi penelitian atas dasar pertimbangan bahwa perumahan Bukit Baruga merupakan perumahan yang diklaim berwawasan lingkungan dengan menyediakan ruang terbuka hijau yang memadai. Namun sejauh mana konsep perumahan berwawasan lingkungan yang diaplikasikan ditinjau dari segi prasarana dasar perumahan dan juga perumahan Bukit Baruga adalah salah satu perumahan terbesar di kota Makassar dengan luas lahan $300 \mathrm{Ha}$ dan yang sudah dikembangkan hingga saat ini adalah sekitar $50 \mathrm{Ha}$.

Penghuni perumahan baruga saat ini sebanyak 2252 kepala keluarga yang terdiri dari 9008 jiwa, dengan jumlah tersebut tentunya aktifitas yang berlangsung di dalam perumahan terbilang padat sehingga membutuhkan dukungan prasarana yang optimal dan berkelanjutan agar tidak menimbulkan dampak negatif bagi lingkungan.

Jenis penelitian yang digunakan adalah penelitian deskriptif komparatif yaitu suatu penelitian yang mendeskripsikan atau menggambarkan perbandingan kondisi ketersediaan prasarana berkelanjutan perumahan dengan studi kepustakaan.

\subsection{Populasi dan Sampel}

Populasi dalam penelitian ini adalah seluruh kepala keluarga (kk) atau penghuni yang mewakili. Sampel sebanyak 100 kk dari 2252 kk yang dipilih menggunakan teknik Cluster sampling yaitu teknik pengambilan sampel berdasarkan zona atau wilayah, pertimbangan peneliti agar hasil pengukuran data dapat secara merata diambil dari semua penghuni perumahan Bukit Baruga Makassar. Kluster wilayah penelitian dibagi berdasarkan umur dari tahap pembangunan unit perumahan, yaitu zona I yang termasuk didalamnya adalah Kawasan Matano dan Mahameru, zona II yang termasuk adalah Kawasan Celebes dan Borneo, zona III adalah Kawasan Andalas.

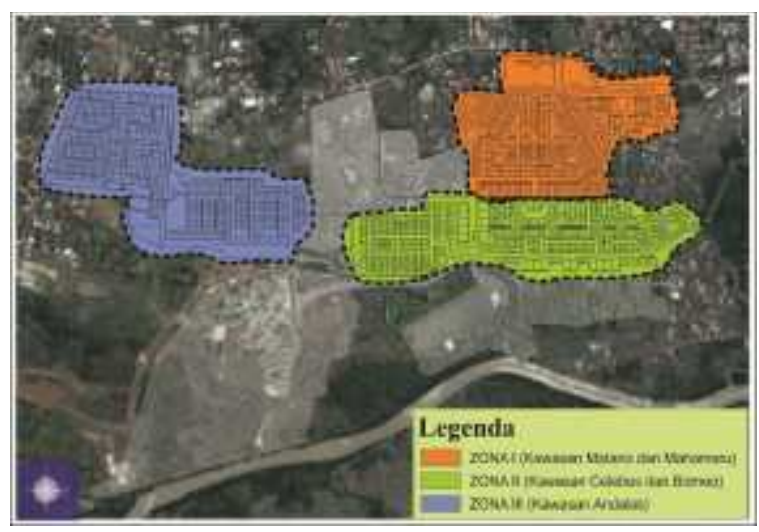

Gambar 1 Peta Pembagian Wilayah Sampel

\subsection{Metode Pengumpulan Data}

Pengumpulan data dilakukan oleh penulis dengan menggunakan observasi dan interview dengan menggunakan kuisioner. Data kepala keluarga (jenis kelamin, umur), data sosial (tingkat pekerjaan, pendidikan, lama bermukim) didapatkan dengan wawancara menggunakan kuesioner. Data ketersediaan prasarana jalan, air bersih, drainase dan sanitasi didapatkan dengan menggunakan metode observasi. Data kuantitas dan kualitas masingmasing prasarana didapatkan dengan menggunakan kuesioner.

\subsection{Analisis Data}

Untuk analisis ketersediaan prasarana teknik analisis data menggunakan analisis deskriptif komparatif. Ketersediaan prasarana berkelanjutan serta tanggapan dan peran serta penghuni perumahan mengenai prasarana berkelanjutan berdasarkan frekuensi hasil interview dengan menggunakan kuisioner pada sampel yang telah ditentukan.

Untuk analisis Analytic Hierarchy Process $(A H P)$ prioritas peningkatan prasarana berkelanjutan perumahan bukit baruga menggunakan metode Analytic Hierarchy Process (AHP). Model Analytic Hierarchy Process (AHP) yang mampu mengakomodir berbagai kriteria yang saling 
mempengaruhi (kriteria majemuk). Kriteria majemuk adalah suatu metode pengambilan keputusan terhadap suatu masalah atau tujuan berdasarkan beberapa kriteria yang berpengaruh terhadap masalah tersebut.

Secara garis besar prosedur AHP dilakukan dalam tiga langkah yaitu :

1. Melakukan pembobotan criteria

2. Melakukan pembobotan alternative

3. Menyusun bobot terhadap keseluruhan susunan

Tabel 1 Contoh Pemberian Nilai untuk Skala Prioritas Kriteria, Sub-Kriteria dan Alternatif

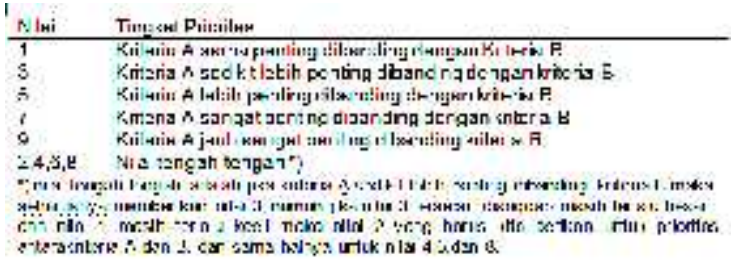

\section{HASIL \& PEMBAHASAN}

\subsection{Hasil Penelitian}

\section{a. Prasarana Transportasi}

\section{1) Kondisi Fisik Ketersediaan}

Jaringan jalan yang tersedia dalam perumahan Bukit Baruga adalah jalan yang menghubungkan antara tiap kluster, unit rumah, dan fasilitas umum pada perumahan Bukit Baruga. Material pengerasan yang diaplikasikan pada jaringan jalan perumahan adalah aspal pada kluster-kluster di zona I dan zona II dimana jenis pengerasan ini tidak mendukung penyerapan air ke dalam tanah dan pada zona III penggunaan jenis pengerasan sudah menggunakan material paving block.
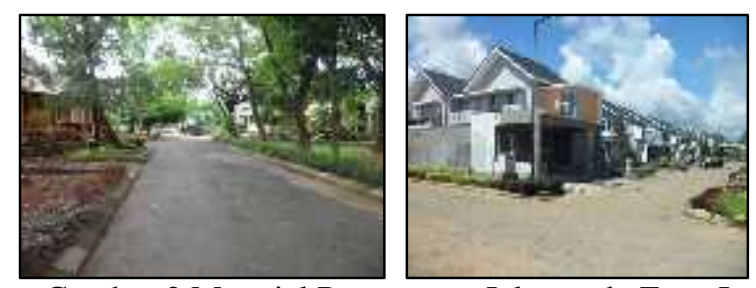

Gambar 2 Material Pengerasan Jalan pada Zona I

Kawasan Matano dan Zona III Kawasan Andalas

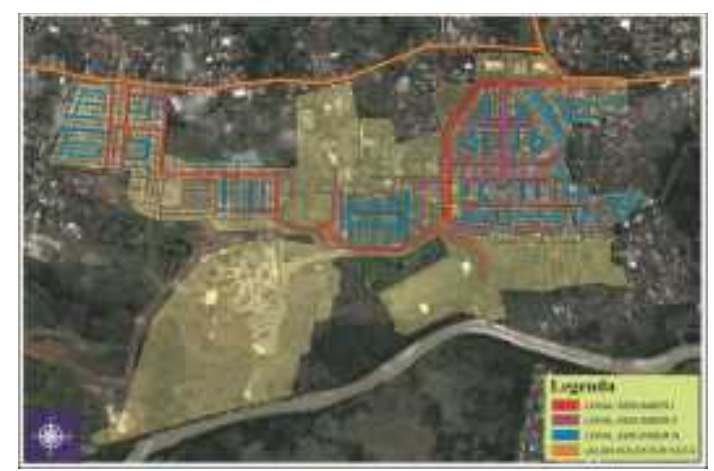

Gambar 3 Peta Hirarki Jaringan Jalan Perumahan Bukit Baruga
Hirarki jalan pada perumahan Bukit Baruga dengan berpedoman pada standar nasional Indonesia SNI 03-6967-2003 terdapat tiga jenis klasifikasi/hirarki jalan yaitu jalan lokal sekunder I, jalan lokal sekunder II dan lokal sekunder III.

Dimensi jalan pada perumahan Bukit Baruga ditinjau menurut hirarki jalan perumahan, standar pengukuran dimensi jalan berdasarkan SNI 03-69672003 tentang persyaratan umum sistem jaringan jalan dan geometrik jalan perumahan.

Moda Transportasi

\begin{tabular}{|c|c|c|c|c|c|c|c|}
\hline \multirow[b]{2}{*}{ I trark jakn } & \multicolumn{7}{|c|}{ Jumen=l yan $(m)$} \\
\hline & Patisary & Eか: & slandar & madar & s:sาdyr & siur & atandar \\
\hline THEI sel:uirtar । & 3750 & $-n, n n$ & $7 . x$ & 10 & - & 20 & $1 \mathrm{mn}$ \\
\hline ikd syutrater II & $2.84^{\circ}$ & $\begin{array}{l}0.00 \\
5.00\end{array}$ & 8.93 & 100 & - & $\begin{array}{l}200 \\
1=0\end{array}$ & 1.00 \\
\hline 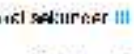 & $573-$ & $\begin{array}{l}-0, n n \\
8.00\end{array}$ & 3 & $\begin{array}{l}1 \omega \\
\text { Tiduk. }\end{array}$ & - & $\begin{array}{l}150 \\
1.50\end{array}$ & $1 \mathrm{mn}$ \\
\hline
\end{tabular}

Berdasarkan data pengukuran pada tabel 2, dimensi jalan perumahan Bukit Baruga memiliki panjang 11.431 meter berdasarkan SPM permukiman panjang jalan minimal 40-60 m/ha jika dengan luas pengembangan wilayah perumahan Bukit Baruga yang efektif adalah 50 ha panjang yang dibutuhkan adalah 3.000 meter sehingga dapat disimpulkan ketersediaan panjang jalan perumahan sangat memadai.

\section{2) Jalur Hijau}

Menurut LEED for neighborhood development (2009) Penanaman pohon dan vegetasi lainnya pada kedua sisi jalan antara batas jalur pejalan dan jalur kendaraan minimal $60 \%$ dari jalan yang ada dengan jarak tanam minimal 10 meter. Pohon memiliki percabangan 2 meter di atas tanah serta bermassa daun padat dan ditanam secara berbaris.

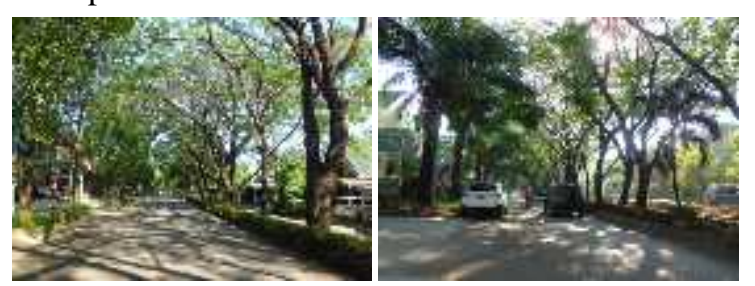

Gambar 4 Eksisting Kondisi Vegetasi Jalur Hijau

Berdasarkan data pada tabel 2 dimensi jalan perumahan Bukit Baruga, jalur hijau pada jaringan jalan perumahan tersedia pada kedua sisi jalan dengan lebar 1,5 meter dan 2 meter dan untuk jalan poros perumahan lokal sekunder I dan jalan kolektor perumahan lokal sekunder II terdapat median jalan yang berfungsi sebagai jalur hijau dengan lebar 1 meter.

\section{3) Jalur Pejalan Kaki dan Sepeda}

Berdasarkan hasil pengamatan di lapangan (lokasi penelitian) jalur pejalan kaki dan jalur pesepeda pada jaringan jalan perumahan tidak tersedia. Mengacu pada standar SNI 03-6967-2003 
tentang geometrik jalan perumahan, menurut fungsi jalan perumahan disyaratkan menyediakan fasilitas pendukung berupa jalur pejalan kaki.

Tabel 3 Tanggapan Penghuni Terhadap Penyediaan Jalur Pejalan Kaki dan Jalur Sepeda

\begin{tabular}{|c|c|c|c|c|c|c|c|c|}
\hline \multirow{3}{*}{ Wicda Tral sfourlasi } & \multicolumn{6}{|c|}{ Wilayah S=mpn! } & \multirow{2}{*}{\multicolumn{2}{|c|}{ liur|an }} \\
\hline & \multicolumn{2}{|c|}{ Zons } & \multicolumn{2}{|c|}{ Zcna I } & \multicolumn{2}{|c|}{ Zon3 III } & & \\
\hline & $\mathrm{N}$ & $1 x_{1}$ & $\mathrm{~N}$ & 's & in & Ku & $N$ & sy. \\
\hline Menclukung & 29 & $8 !, 9$ & 18 & $b b ; 9$ & 23 & $\ddot{\theta i a}, i$ & 11 & 11 \\
\hline Tidak msndukung & 4 & $: 2,1$ & 15 & 44.1 & 10 & 39.3 & 29 & 29 \\
\hline Toisl & 33 & 150 & 34 & 100 & 33 & 100 & $-\infty$ &.$\infty$ \\
\hline
\end{tabular}

Dari hasil tabel 2, berdasarkan tanggapan masyarakat terhadap penyediaan jalur pejalan kaki pada perumahan Bukit Baruga sebanyak $71 \%$ atau sebanyak 71 orang mendukung hal tersebut dengan alasan keamanan dan kenyamanan untuk penghuni rumah saat melakukan jogging/berjalan kaki dan juga bersepeda pada jalan perumahan dan juga untuk anak-anak saat bermain di luar rumah.

\section{4) Drainase}

Berdasarkan Keputusan Menteri Pekerjaan Umum Nomor 20 tahun 1986, Saluran pembuangan air hujan dapat merupakan saluran terbuka atau tertutup. Saluran terbuka terbentuk $1 / 2$ lingkaran dengan ukuran minimum diameter $20 \mathrm{~cm}$, bentuk bulat telur minimum $20-30 \mathrm{~cm}$, kemiringan saluran minimum $2 \%$ dan kedalaman saluran minimum 40 cm. Pada perumahan Bukit Baruga Terdapat dua dimensi drainase yaitu pertama lebar $40 \mathrm{~cm}$ dengan kedalaman saluran $\pm 80 \mathrm{~cm}$ berfungsi sebagai saluran pengalir dan dimensi drainase kedua memiliki lebar $100 \mathrm{~cm}$ dengan kedalaman saluran \pm $100 \mathrm{~cm}$ yang berfungsi sebagai saluran pengumpul. Jika mengacu pada Kepmen PU No.20 tahun 1986 kondisi dimensi drainase perumahan Bukit Baruga termasuk dalam kategori baik memenuhi standar dimensi minimum yang diisyaratkan.

\section{5) Air Bersih}

\section{- Sumber air bersih}

Berdasarkan hasil observasi lapangan dan interview sumber air bersih yang disediakan oleh pihak pengembang perumahan Bukit Baruga ada dua jenis yaitu air tanah dan PDAM. Penggunaan sumber air tanah ini menggunakan instalasi pengolahan air tanah yang disediakan pengembang untuk memenuhi kebutuhan air bersih warga penghuni perumahan pada awal pengembangan sebab jaringan PDAM belum tersedia pada perumahan Bukit Baruga.

\section{- Distribusi air bersih perumahan}

Berdasarkan tabel 2 distribusi air bersih yang diolah pihak pengelola perumahan menuju tiap unit hunian pada perumahan Bukit Baruga termasuk kategori cukup baik dalam pendistribusiannya, tiap warga mendapatkan air bersih sesuai kebutuhannya.

\section{6) Sanitasi (sampah dan air limbah)}

- Sistem penanganan sampah perumahan

Penanganan sampah pada perumahan Bukit Baruga dikelola oleh pihak pengembang perumahan berdasarkan beban iuran kebersihan tiap bulan yang dibayarkan penghuni kepada pihak pengembang. Sistem penanganan sampah perumahan yang dilakukan pihak pengembang dengan menyediakan armada pengangkutan sampah. Berdasarkan hasil wawancara dengan pihak pengembang Armada pengangkutan sampah yang disiapkan oleh pihak pengembang PT. Asrinusa Development sebanyak 4 unit armada yang bertugas mengangkut sampah dari tempat penampungan sementara tiap rumah pada semua kluster perumahan.

\section{- Pengolahan sampah berkelanjutan}

Pada perumahan Bukit Baruga perlu kerjasama antara pihak pengembang perumahan selaku pengelola yang bertanggung jawab terhadap kebersihan perumahan dan warga penghuni perumahan selaku penghasil sampah yang berperan penting untuk menerapkan konsep 3R (reduce,reuse, dan recycle) dalam pengelolaan persampahan perumahan. Maka perlunya diketahui pola kebiasaan warga penghuni dalam pengelolaan persampahan, sehingga dapat diketahui kebutuhan yang dapat diakomodasi untuk mencapai pengelolaan sampah yang ideal.

Tabel 4 Cara Pengelolaan dan Pembuangan Sampah Penghuni Perumahan

\begin{tabular}{|c|c|c|c|c|c|c|c|c|}
\hline \multirow{3}{*}{ Katager! } & \multicolumn{6}{|c|}{ Wilayah Sampel } & \multirow{2}{*}{\multicolumn{2}{|c|}{ Jurrial: }} \\
\hline & & กล: I & & Hitil & & i III: & & \\
\hline & $N$ & $x$ & y & 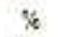 & $\mathrm{N}$ & $\%$ & N & $\%$ \\
\hline Dipilah dahulu & 2 & 61 & 2 & 5.8 & & & 1 & 1 \\
\hline Lanasung dibuang & 31 & $93, y$ & 32 & 91.1 & 33 & 100 & 86 & 96 \\
\hline Tolial & 39 & 100 & 34 & 100 & 33 & 100 & 100 & 100 \\
\hline
\end{tabular}

Berdasarkan hasil kuisioner pada tabel 3, responden cenderung langsung membuang sampah yang dihasilkan tanpa memilahnya terlebih dahulu. Pengelolaan sampah penghuni perumahan pada hasil survai di atas menunjukkan tidak diterapkannya konsep berkelanjutan dalam penanganannya.

\section{- Pengolahan air limbah}

Berdasarkan hasil observasi lapangan dan wawancara dengan pihak pengembang tidak terdapat fasilitas instalasi pengolahan air limbah (IPAL) yang disediakan oleh pihak pengembang perumahan.

\section{b. Prioritas Peningkatan Prasarana}

Untuk menentukan prioritas peningkatan prasarana berkelanjutan di perumahan Bukit Baruga Makassar dengan menggunakan analisis AHP (Analitic Hierarchy Process) dengan berdasarkan pada skema analisis dan pertimbangan hasil kuesioner. 


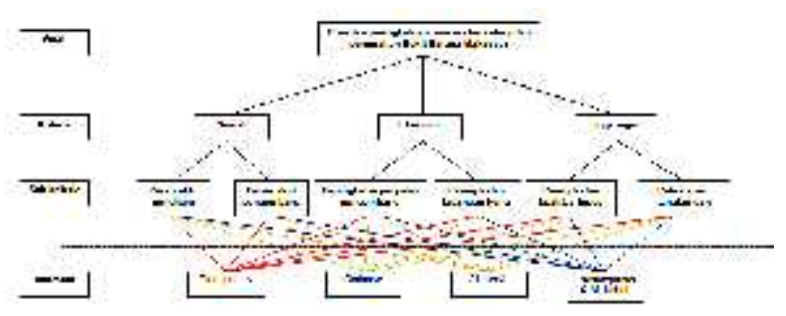

Gambar 5 Skema Analisis AHP (Analytic Herarchy Process)

Menentukan prioritas pengembangan Prasarana berkelanjutan di Perumahan Bukit Baruga dengan melakukan perhitungan bobot total masing-masing alternatif terhadap sub kriteria dan kriteria. Cara menentukan bobot total adalah dengan melakukan perkalian antara bobot kriteria, sub kriteria dan alternatif pada sub kriteria (Bobot Total $=\mathrm{A} \times \mathrm{B} \times$ C), dengan keterangan $\mathrm{A}=$ Bobot Kriteria, $\mathrm{B}=$ Bobot Sub Kriteria, C = Bobot Alternatif pada sub kriteria.

Pada tabel 5 merupakan penjelasan dari hasil resume atau penyatuan nilai prioritas pada masingmasing kriteria, sub-kriteria, dan alternatif. Pada baris pertama tabel 5 menunjukkan nilai prioritas untuk perbandingan antara kriteria sosial, ekonomi, dan lingkungan. Untuk baris kedua menunjukkan nilai priroritas perbandingan sub-kriteria dengan masing-masing kriterianya sesuai dengan skema analisis AHP yang sudah dibuat. Pada baris ketiga menunjukkan nilai prioritas masing-masing alternatif dengan pertimbangan dari sub-kriteria di atasnya.

Seperti yang telah dijelaskan mendapatkan bobot total dengan melakukan perkalian antara bobot kriteria, sub kriteria dan alternatif pada sub kriteria. Pada tabel 6 menunjukkan hasil perkalian dari tabel 5 yang kemudian dijumlahkan untuk mendapatkan nilai bobot prioritas.

Tabel 5 Tabel Resume Penilaian Pembobotan Kriteria, Sub Kriteria dan Alternatif Sub Kriteria

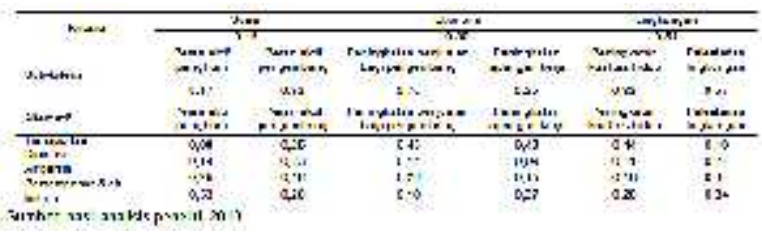

Tabel 6 Penjumlahan Bobot Total Secara Keseluruhan untuk Menentukan Total Bobot Prioritas

\begin{tabular}{|c|c|c|c|c|c|c|c|}
\hline \multirow{3}{*}{ 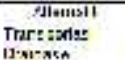 } & \multicolumn{6}{|c|}{ J-nil2าt:k:t } & \multirow{3}{*}{$\begin{array}{l}\text { Tor } \\
03 \\
111\end{array}$} \\
\hline & e,ces & $2,2 \pi 0$ & 200 & $0, \alpha \sigma$ & c,aec & $20 x$ & \\
\hline & ligs & at:a & 4 4xו1 & linesis & (1) तम & IแM & \\
\hline$\lambda:$ : & lesesi & 1250 & bat & Int: & $w<x$ & $4 \%$ & ג: \\
\hline 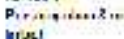 & apd & anen & ליחמ & mon & pros: & $4 \cdot 5$ & $n \pi$ \\
\hline$T_{m}=$ & $\operatorname{sinez}$ & $a \pi$ & דינ & $\mathrm{M} \times \mathrm{CH}$ & $817 \pi$ & ง 352 & $\cdot m$ \\
\hline
\end{tabular}

Berdasarkan hasil perhitungan Bobot total pada tabel 6, maka prioritas peningkatan prasarana berkelanjutan di perumahan Bukit Baruga.
Tabel 7 Prioritas Peningkatan Prasarana Berkelanjutan di Perumahan Bukit Baruga

\begin{tabular}{|c|c|c|c|}
\hline $\mathrm{N}: \mathrm{s}$ & 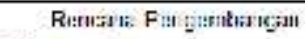 & Toral & Praitus \\
\hline T & Tranripetרs & 9,31 & $T$ \\
\hline$?$ & sersenparar y Aur limbeר & $3,2 \ell$ & 1 \\
\hline j & tartih & 325 & IIII \\
\hline 4 & Drair & 0,17 & $v$ \\
\hline
\end{tabular}

Sumber: hasil analisis peneliti, 2013

\section{c. Pembahasan Prasarana Berkelanjutan}

Penelitian ini menunjukkan ketersediaan prasarana perumahan Bukit Baruga belum sepenuhnya memenuhi konsep berkelanjutan terlihat dengan beberapa point berdasarkan komparasi terhadap kajian pustaka berkelanjutan yang belum terpenuhi. Prioritas peningkatan berdasarkan metode analisis AHP didapatkan prasarana transportasi menjadi prioritas utama.

Prasarana jalan dan transportasi pada perumahan Bukit Baruga sudah mendekati konsep prasarana yang berkelanjutan / ramah lingkungan namun masih terdapat beberapa point yang bersifat tidak berkelanjutan. Penerapan yang sudah bersifat berkelanjutan antara lain terlihat pada ketersediaan jaringan jalan dengan hirarki yang teratur sesuai fungsi jalannya dan juga dimensi jalan yang sudah sangat baik mengikuti ketentuan standar SNI 036967-2003 tentang geometrik jalan perumahan dan standar pelayanan minimal (SPM) permukiman.

Terlihat juga pada kondisi jalur hijau jaringan jalan perumahan berdasarkan LEED for neighborhood development (2009) dimana Penanaman pohon dan vegetasi lainnya pada kedua sisi jalan antara batas jalur pejalan dan jalur kendaraan minimal $60 \%$ dari jalan yang ada dengan jarak tanam minimal 10 meter sudah sesuai. Beberapa point yang masih bersifat tidak berkelanjutan terlihat melalui kondisi jaringan jalan perumahan pada wilayah penelitian zona I dan II yang permukaannya sebagian besar masih menggunakan aspal karena aspal tidak dapat meresapkan limpasan air hujan langsung ke dalam tanah, namun sebagian kluster baru pada zona Andalas perumahan sudah mengaplikasikan penggunaan paving block pada permukaan jalannya. Tingginya kecenderungan penghuni menggunakan moda kendaraan bermotor sebagai alat transportasi lokalnya bisa membuat kualitas lingkungan yang tidak sehat dengan dampak polusi udara, kebisingan, dan pemborosan bahan bakar minyak. Hal ini karena tidak adanya fasilitas jalan yang mendukung pergerakan berjalan kaki dan bersepeda.

Kemudian ketersediaan jaringan drainase berkelanjutan pada perumahan Bukit Baruga diketahui dari segi kondisi dan fungsi jaringan drainase perumahan masih dalam keadaan baik. fungsi jaringan drainase juga mampu mengalirkan air limpasan dengan baik dan menjaga permukaan jalan dari genangan air / banjir. Selain dari kondisi dan fungsi jaringan drainase yang baik berdasarkan 
observasi lapangan pada sistem konstruksi jaringan drainase perumahan belum diterapkannya suatu sistem ekodrainase pada jaringan drainase perumahan Bukit Baruga dimana sistem ekodrainase dibutuhkan untuk mendukung pemanfaatan air limpasan permukaan dengan diresapkan secara perlahan ke dalam tanah.

Sumber air bersih yang tersedia berasal dari perusahaan air minum daerah (PDAM) yang dikoneksikan oleh pihak pengembang perumahan menuju jaringan distribusi yang disiapkan sudah mendukung konsep berkelanjutan pada perumahan Bukit Baruga dalam hal penggunaan air bersih yang lebih dapat dikontrol sesuai keperluan sehingga dapat menghemat penggunaannya serta mutu air bersih yang lebih terjaga yang dapat mendukung kesehatan warga perumahan. Kemudian sumber air bersih alternatif dengan menggunakan air tanah pada perumahan Bukit Baruga perlu diperhatikan secara khusus dengan menjaga daerah-daerah konservasi dan retensi air seperti ruang terbuka hijau yang telah tersedia agar tidak beralih fungsi dikemudian hari.

Kondisi persampahan pada perumahan Bukit Baruga sudah cukup baik dalam ketersediaan fasilitas pendukung seperti tersedianya tempat penampungan sampah sementara ditiap unit hunian dan armada pengangkutan sampah yang beroperasi mengangkut sampah perumahan. Sistem pengangkutan sampah perumahan juga terlihat optimal dalam menangani timbunan sampah perumahan melalui manajemen pengangkutan sampah yang terjadwal dan konsisten dalam pengangkutannya sehingga kawasan perumahan senantiasa bersih dari timbunan sampah. Disamping ketersediaan fasilitas dan penanganan sampah yang sudah cukup baik masih terdapat kekurangan pada tingkat kesadaran masyarakat dalam mendukung manajemen persampahan yang berkelanjutan.

Masyarakat penghuni perumahan mempunyai peranan penting dalam berjalannya sistem pengolahan sampah berkelanjutan dengan prinsip reduce, reuse, dan recycle, dimana masyarakat penghuni sebagai penghasil sampah utama diharapkan mengelompokan / memilah terlebih dahulu jenis sampah yang akan dibuang. penghuni perumahan dengan alasan tidak mempunyai waktu dan menganggap tanggung jawab pengolahan sampah tersebut adalah urusan pihak pengembang karena sudah merasa memenuhi kewajibannya membayar iuran kebersihan tiap bulannya. Kondisi pengelolaan air limbah perumahan masih terbilang minim dengan tidak tersedianya fasilitas instalasi pengolahan air limbah (IPAL) baik on site maupun off site. Saluran air limbah grey water menyatu dengan saluran air hujan sehingga berpotensi besar mencemari lingkungan.

\section{KESIMPULAN \& SARAN}

Dapat disimpulkan Ketersediaan prasarana perumahan Bukit Baruga belum sepenuhnya memenuhi standar berkelanjutan. Pada prasarana jalan Material pengerasan masih menggunakan aspal sehingga perlu pengaplikasian material pengerasan dari bahan yang mempunyai celah untuk air meresap ke dalam tanah seperti paving block dan grass block.

Moda transportasi didominasi Penggunaan kendaraan bermotor berdampak pada polusi lingkungan dan pemborosan energi sehingga perlu Mendorong penggunaan kendaraan tidak bermotor dalam aktifitas jangkauan penghuni ke sarana / fasilitas umum perumahan dengan menyiapkan jalur pedestrian yang terintegrasi dengan jaringan jalan perumahan.

Sistem drainase masih menggunakan drainase konvensional perlu menerapkan prinsip ekodrainase pada sistem konstruksi drainase yang mampu mendayagunakan air limpasan di tempat seperti fasilitas penahan air hujan, rainwater harvest-roof dan kolam / sumur resapan.

Sumber air bersih berasal dari PDAM dan sumber air bersih alternatif dari pengolahan air tanah yang disiapkan pihak pengembang, penggunaan air tanah perlu dijaga dan diperhatikan, serta ruang terbuka hijau yang telah tersedia dan upaya-upaya konservasi air yang telah dilakukan jangan sampai beralih fungsi dan tidak diperhatikan dikemudian hari.

Kemudian sistem pengangkutan sampah tidak dilakukan dengan memilah / mengelompokkan jenis sampah terlebih dahulu sehingga pengolahan sampah menjadi mahal dan sulit serta berpotensi mencemari lingkungan dan membahayakan kesehatan. Perlu adanya peran serta warga perumahan dalam mengelola sampah dengan prinsip berkelanjutan (seperti program 3R, komposter, pengolahan sampah organik dan anorganik) sehingga berdampak pada pengurangan sampah dan resiko kerusakan lingkungan.

Sistem pengolahan air limbah perumahan tidak disediakan oleh pengembang sehingga potensi mencemari lingkungan sangat besar. Pihak pengembang perlu menyediakan sistem pengolahan air limbah terpusat (off site) agar kontrol terhadap resiko pencemaran lingkungan dapat dilakukan.

\section{DAFTAR PUSTAKA}

Achmad, Aditya, Muhammad. (2011). Pengelolaan Sampah Berbasis Masyarakat Di kota Makassar, Studi Kasus Kelurahan KassiKassi RW 7. Makassar: Tesis PPS Unhas.

Badan Standarisasi Nasional. SNI 03-6967-2003. Persyaratan umum sistem jaringan dan geometrik jalan perumahan.

Burhanuddin, Fathurrahman. (2012). Prioritas Pengembangan Infrastruktur Berkelanjutan di Pulau Barrang Lompo Dengan Menggunakan Metode Analisis AHP (Analytic Hierarchy Process). Makassar: Tesis PPS Unhas. 
Direktorat Jenderal Cipta Karya. (1998). Pedoman Teknis Prasarana Jalan Perumahan (sistem Jaringan dan Geometri Jalan)

Massikki, Nadjib, Muh. (2005). Analisis Ketersediaan Sarana dan Prasarana pada Lingkungan Permukiman. Majalah Ilmiah "MEKTEK" Tahun VII No. 3, September.

Mark, A., Benedict, Ph.D.; Edward, T., McMahon, J.D. (2001). Green Infrastructure: Smart Conservation for the 21 st Century.

Robert, Kansley. (2006). Statistik untuk penelitian. Jakarta: Rajagrafindo persada.

Keputusan Menteri Pekerjaan Umum No. 20 tahun 1986 tentang Pedoman Teknik Pembangunan Perumahan Sederhana Tidak Bersusun

Keputusan Menteri Permukiman dan Prasarana Wilayah. No. 534/KPTS/M/2001. Standar Pelayanan Minimal Permukiman.

LEED for Neighborhood Development Rating System. (2009). U.S. Green Building Council.Washington, DC.

Thomas, L., Saaty. (2008). Decision Making with the Analytic Hierarchy Process. Int. J. Services Sciences, Vol.1, No. 1. (http://colorado.edu/geography/), Diakses 07 Maret 2012. 